\title{
COMPUTED TOMOGRAPHY GUIDED TRANSTHORACIC FINE NEEDLE ASPIRATION CYTOLOGY IN THE DIAGNOSIS OF SONOGRAPHICALLY NON-APPROACHABLE INTRATHORACIC MASSES - A STUDY OF 100 CASES
}

\author{
SARKER RN ${ }^{1}$, RABBI AF$^{2}$, HOSSAIN A $^{3}$, QUDDUS MA ${ }^{4}$, CHOWDHURY N ${ }^{5}$, SARKER T ${ }^{6}$, KUMU FK $^{7}$, \\ AZAD KAK ${ }^{8}$
}

\begin{abstract}
:
Objective: To evaluate the diagnostic efficacy of computed tomography (CT) guided transthoracic fine needle aspiration cytology (FNAC) in the diagnosis of intrathoracic masses not approachable by ultrasound.
\end{abstract}

Materials and Methods: CT guided FNAC of intrathoracic masses was done in 100 patients and they were followed up to the final diagnosis. The diagnostic accuracy, sensitivity, specificity, positive and negative predictive values of the procedures were calculated.

Results: The sensitivity, specificity, accuracy, positive predictive value and negative predictive value of CT guided transthoracic FNAC were 93.85\%, 100\%, 96\%, 100\% \& 89.74\% respectively for the diagnosis of sonographically nonapproachable malignant intrathoracic masses and 94.29\%, 98.46\%, 97\%\%, 97.06\% \& 96.97\% respectively for benign intrathoracic masses.

Conclusion: CT guided transthoracic FNAC is a highly sensitive and specific procedure in the diagnosis of intrathoracic masses that are not approachable by ultrasound.

Keywords: Computed tomography, Fine needle aspiration cytology, Intrathoracic masses.

J Dhaka Med Coll. 2011; 20(1) : 25-31.

\section{Introduction:}

Intrathoracic mass is a common problem encountered by the clinicians worldwide as well as in Bangladesh but it is difficult to diagnose correctly. Many techniques have been used in the diagnosis of the intrathoracic masses by obtaining tissue materials. ${ }^{1}$

Fine needle aspiration (FNA) is a method of taking cytology sample by means of a fine needle attached with a syringe. Fine needle aspiration cytology (FNAC) is a diagnostic technique which involves study of the cell smears prepared from FNA material. It is much easier and less traumatic technique than excision biopsy and widely employed in cytological diagnosis with good diagnostic accuracy. ${ }^{2,3}$ FNAC of deep organs needs the aid of ultrasonography or computed tomography as a guidance to perform it. ${ }^{4-6}$ Ultrasound guided FNAC has been used as a diagnostic procedure of peripheral lung masses ${ }^{7-9}$ but deep intrathoracic masses cannot be imaged by ultrasonography.

CT guided biopsy was first reported in 1976 and since then numerous reports have shown CT guided transthoracic FNAC to be an accurate

1. Dr. Robindra Nath Sarker, Assistant Professor, Department of Radiology and Imaging, Dhaka Medical College and Hospital, Dhaka.

2. Dr. Akanda Fazle Rabbi, Lecturer, Dhaka Medical College, Dhaka.

3. Prof. Ahmad Hossain, Ex-Professor Department of Radiology and Imaging, Dhaka Medical College and Hospital, Dhaka.

4. Prof. MA Quddus, Ex-Professor Dept. of Radiology and Imaging, Dhaka Medical College and Hospital, Dhaka.

5. Dr. Noman Chowdhury, Assistant Professor, Department of Radiology and Imaging, Dhaka Medical College and Hospital, Dhaka.

6. Dr. Taposhi Sarker, Registrar, Department of Radiology and Imaging, Apollo Hospitals, Dhaka.

7. Dr. Farhana Kamal Kumu, MPhil (Thesis) student, Department of Radiology and Imaging, Dhaka Medical College, Dhaka.

8. Prof. Khan Abul Kalam Azad, Professor of Medicine, Dhaka Medical College, Dhaka.

Correspondence: Dr. Robindra Nath Sarker, Assistant Professor, Department of Radiology and Imaging, Dhaka Medical College and Hospital, Dhaka. Cell Phone: +880171100310036, E-mail: robinsarkerk45@yahoo.com 
and safe method for the diagnosis of intrathoracic masses. CT guidance permits fine needle aspiration of nearly all lesions that are visible on CT scans, regardless of size or position ${ }^{10}$. The vast majority of lung malignancies can be confidently diagnosed with cytomorphological characterization in right clinical context. ${ }^{11}$ It can accurately sub-classify the type of bronchogenic carcinoma and suggest a possible primary site of metastatic lung tumours. Vascular \& cardiac structures are well demonstrated \& safely avoided. ${ }^{12}$ Contrast enhancement differentiates the low-density center from those regions more likely containing viable tumor cells. An extra-pleural approach to mediastinal lesions can also be achieved. This can be invaluable in patients whose clinical condition would make a small pneumothorax life threatening. ${ }^{13}$ Moreover, CT guided transthoracic FNAC can be used safely as an out door procedure. So, some investigators recommend $\mathrm{CT}$ guided FNAC as the initial method of diagnosis of deep intrathoracic masses ${ }^{11}$. Although fluoroscopically guided FNAC of central lung masses is an accepted diagnostic method but is not routinely practiced in Bangladesh. On the other hand CT scan is available in many centers in the country and has been extended up to some districts. So CT guided transthoracic FNAC can be employed as suitable alternative for the diagnosis of sonographically non-approachable intrathoracic masses in our country as it is less costly, relatively easy, rapid and safe.

CT guided FNAC is a relatively new diagnostic procedure in Bangladesh. Diagnosis of central lung lesion by CT guided transthoracic FNAC is made only in a few centers. Considerable controversy still exists concerning the relative merits of transthoracic FNAC. No research work has yet been done in our country regarding its efficacy. So this study was carried out to know and validate the $\mathrm{CT}$ guided transthoracic FNAC as a modality for the diagnosis of intrathoracic masses nonapproachable by USG.

\section{Materials and Methods:}

This cross-sectional observational study was carried out at the Department of Radiology and
Imaging, Dhaka Medical College and Hospital, Dhaka during the period of July 2006 to February 2010 on 100 patients with chest xray and $\mathrm{CT}$ findings suggestive of intrathoracic mass who attended the above-mentioned hospital for treatment. All of them were conscious cooperative patients with stable clinical condition having sonographically nonapproachable intrathoracic centrial masses and without evidence or clinical suspicion of bullous and emphysaematous change, diffuse lung diseases, coagulopathy, vascular lesion, pulmonary arterial hypertension and ecchinococcus infection. Necessary investigations were done for exclusion of the above clinical conditions e.g. blood for TC, DC, ESR, $\mathrm{Hb} \%$, platelet count, BT , CT and prothrombin time and X-ray chest PA and lateral view. USG of chest was done to confirm that it was not approachable by USG. Recent plain and contrast CT of chest made available prior to CT guided FNAC.

FNA was done by the investigators after explaining the risks and benefits of the procedure to the patients and written consent taken from each patient. Then an axial scan of area of interest only was done to locate the lesion (distance from the surface and needle angulations); the best approach (supine or prone or lateral) was judged and the skin puncture site was marked with a radio opaque marker. After cleaning and draping, local anaesthetic ( $2 \%$ xylocaine) was infiltrated at the puncture site deep to pleura. Then a 23gauge spinal needle was inserted during suspended respiration, directing its tip towards the lesion. With the tip of the needle located within, a repeat slice of the area of interest was taken to check the exact position of its tip.10- $\mathrm{ml}$ syringe was attached to a short rubber tube collected from JMS saline set. Another end of rubber tube was attached to needle's hub and the plunger was pulled back maintaining a sustained negative suction of about $08 \mathrm{cc}$. After 4 to 5 vigorous movement of needle inside the mass suction was relieved and the needle pulled out. If the aspirate material was not satisfactory, the needle was introduced for the second time. The aspirate was smeared on slides and quickly immersed 
in $95 \%$ alcohol to prevent cellular distortion from drying. These were stained for one hour with the papanicolaou technique and examined by a cytopathologist.

An upright expiratory chest film was taken for all patients one hour after FNA to rule out postFNA pneumothorax. If any amount of pneumothorax developed, patient was kept under observation for 24 hours and a chest Xray PA view was done after $24 \mathrm{hr}$ to rule out any subsequent development of pneumothorax. In case of no complication, patient was discharged.

All patients were followed up from examination to the final diagnosis. The final diagnosis was determined from examination of surgical specimen, biopsy from true cut needle or by bronchoscope, therapeutic response, same diagnosis made elsewhere in the body in case of metastatic lesions and from clinical followup. A comparison was done between cytological diagnosis and final diagnosis. Statistical analysis was done to see the diagnostic value of CT guided FNAC for the diagnosis of sonographically nonapproavhable intrathoracic mass by calculating sensitivity, specificity, accuracy, positive and negative predictive values for malignant and benign lesions separately.

\section{Observation and Results:}

Among 100 patients with intrathoracic mass, the age ranged between 25-85 years with highest number of patients in the age group 46-55 years. There were 77 men (77\%) and 23 women (23\%). Lung was the most common site of the masses (67\%). Other sites of the lesions are summarized in Table I.

Table-I

Sites of intrathoracic masses $(n=100)$

\begin{tabular}{lcc}
\hline Site & No. of patients & Percentage \\
\hline Pulmonary & 67 & $67 \%$ \\
Hilar & 14 & $14 \%$ \\
Mediastinal & 19 & $19 \%$ \\
\hline Total & 100 & $100 \%$ \\
\hline
\end{tabular}

Of the 100 patients underwent CT-guided FNA, definitive diagnosis for 5 patients could not be made by cytopathologists due to insufficient tissue material. The diagnosis of rest of 95 patients is given in the Table II. Squamous cell carcinoma was most prevalent among the spectrum of cytological diagnoses followed by adenocarcinoma. FNAC diagnosed 61 cases as malignant intrathoracic mass, 34 as benign lesions and 05 was undiagnosed due to inadequate tissue material.

The final diagnosis and means of eventual diagnosis (Open biopsy, bronchoscopic biopsy, therapeutic response, same diagnosis made elsewhere in the body) of 100 patients included in this study are given in Table III. Final diagnosis revealed the undiagnosed cases where tissue material was insufficient by FNAC. Among those, two cases were diagnosed as squamous cell carcinoma, one metastatic lesion and two benign granulomatous lesions. One case diagnosed as benign lesion by FNAC subsequently diagnosed as metastatic lesion. So, finally 65 patients were diagnosed as malignant and 35 cases as benign. The highest number of cases was squamous cell carcinoma followed by adenocarcinoma.

\section{Table-II}

CT guided FNAC diagnosis of intrathoracic masses ( $n=100)$

\begin{tabular}{lcc}
\hline Findings & $\begin{array}{c}\text { No. of } \\
\text { patients }\end{array}$ & Percentage \\
\hline Squamous cell carcinoma & 29 & $29 \%$ \\
Adenocarcinoma & 16 & $16 \%$ \\
Small cell mcarcinoma & 06 & $06 \%$ \\
Large call carcinoma & 03 & $03 \%$ \\
Metastatatic carcinoma & 07 & $07 \%$ \\
Benign lesions & 34 & $34 \%$ \\
Non diagnosed & 05 & $05 \%$ \\
(inadequate tissue) & & \\
\hline Total & 100 & $100 \%$ \\
\hline
\end{tabular}


Table-III

Final diagnosis of intrathoracic masses $(n=100)$

\begin{tabular}{lcl}
\hline Findings & No. of patients & Means of eventual diagnosis \\
\hline Squamous cell carcinoma & 31 & Open biopsy, Bronchoscopic biopsy \\
Adenocarcinoma & 16 & Open biopsy, Bronchoscopic biopsy \\
Small cell carcinoma & 06 & Bronchoscopic biopsy, Therapeutic response. \\
Large call carcinoma & 03 & Open biopsy, bronchoscopic biopsy. \\
Metastatatic carcinoma & 09 & Same diagnosis made elsewhere in the body. \\
Benign lesion & 35 & Therapeutic response. \\
\hline Total & 100 & \\
\hline
\end{tabular}

The validity parameters of CT guided FNAC as a diagnostic modality is shown in Table IV. The sensitivity, specificity, accuracy, positive predictive value and negative predictive value of CT guided transthoracic FNAC were $93.85 \%$, $100 \%, 96 \%, 100 \% \& 89.74 \%$ respectively for malignant intrathoracic masses and $94.29 \%$, 98.46\%, 97\%\%, 97.06\% \& 96.97\% respectively for benign masses.

\section{Table-IV}

Validity parameters of CT guided FNAC

\begin{tabular}{lcc}
\hline $\begin{array}{l}\text { Validity } \\
\text { parameters }\end{array}$ & $\begin{array}{c}\text { For malignant } \\
\text { intrathoracic } \\
\text { masses }\end{array}$ & $\begin{array}{c}\text { For benign } \\
\text { intrathoracic } \\
\text { masses }\end{array}$ \\
\hline Sensitivity & $93.85 \%$ & $94.29 \%$ \\
Specificity & $100 \%$ & $98.46 \%$ \\
Accuracy & $96 \%$ & $97 \% \%$ \\
PPV & $100 \%$ & $97.06 \%$ \\
NPV & $89.74 \%$ & $96.97 \%$ \\
\hline
\end{tabular}

CT guided FNAC proved to be a safe procedure. Out of 100 cases no complications arose in $67 \%$ cases. 17 cases complained pain at puncture site. Small pneumothorax was seen in 12 cases. Single episode haemoptysis was seen in two cases. However, none of the complications required any treatment. Complications of CT guided FNAC is shown in table V.

\section{Table-V}

Complications of CT guided FNAC ( $n=100)$

\begin{tabular}{lcc}
\hline Complication & $\begin{array}{c}\text { No. of the } \\
\text { patients }\end{array}$ & Percentage \\
\hline Pain at Puncture site & 18 & $18 \%$ \\
Small Pneumothorax & 13 & $13 \%$ \\
Haemoptysis & 02 & $02 \%$ \\
No complication & 67 & $67 \%$ \\
Total & 100 & $100 \%$ \\
\hline
\end{tabular}

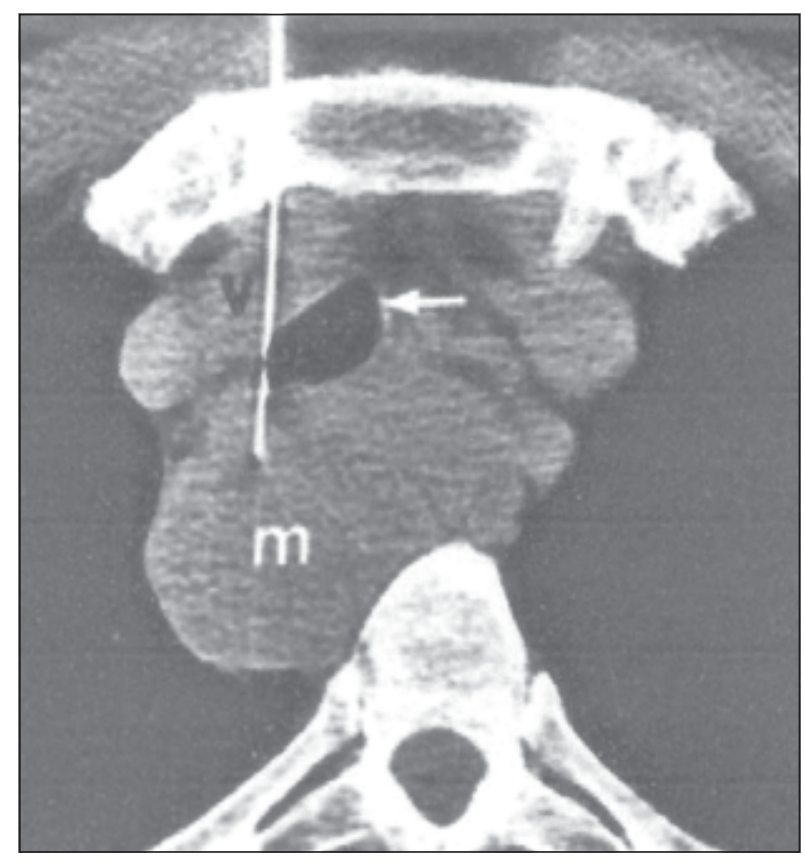

Fig.-1: CT-FNA of a posterior mediastinal mass. 


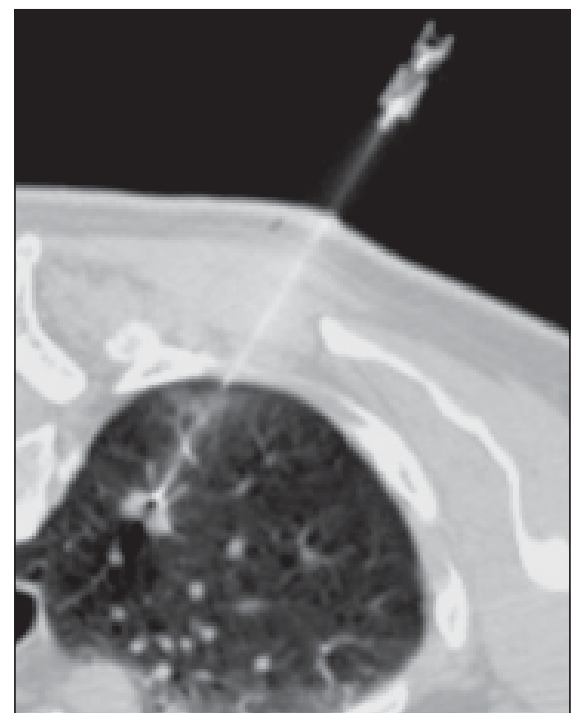

Fig.-2: CT-FNA of a solitary pulmonary nodule.

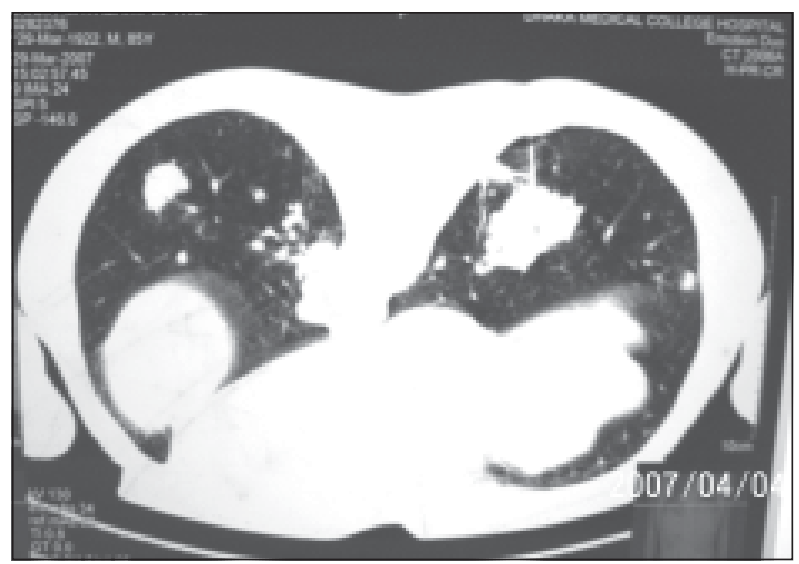

Fig.-3: CT-FNA of lung mass.

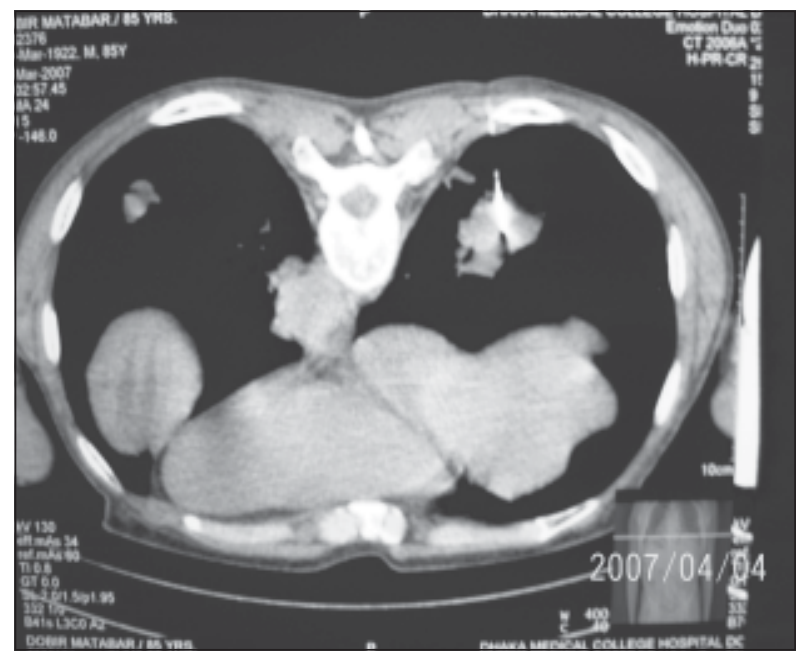

Fig.-4: CT-FNA of an intrathoracic central mass lesion.

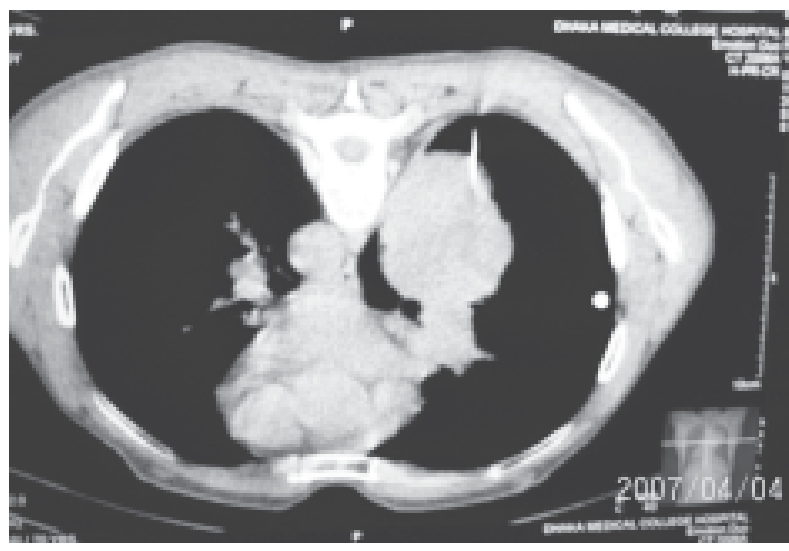

Fig.-5: CT-FNA of a central intrathoracic mass lesion.

Table VI

Validity parameters of present study compared with some previous studies

\begin{tabular}{lcccccc}
\hline $\begin{array}{l}\text { Validity } \\
\text { parameters }\end{array}$ & $\begin{array}{c}\text { Singh } \\
\text { et al }\end{array}$ & $\begin{array}{c}\text { Stanley } \\
\text { et al }\end{array}$ & $\begin{array}{c}\text { Haramati } \\
\text { et al }\end{array}$ & $\begin{array}{c}\text { Mohammad } \\
\text { et al }^{12}\end{array}$ & $\begin{array}{c}\text { Sonnenburg } \\
\text { van et al }\end{array}$ & $\begin{array}{c}\text { Present } \\
\text { Study }\end{array}$ \\
\hline Sensitivity & $92.6 \%$ & $96.6 \%$ & $84 \%$ & $95.6 \%$ & $82.7 \%$ & $93.85 \%$ \\
Specificity & $100 \%$ & $100 \%$ & $100 \%$ & $100 \%$ & $100 \%$ & $100 \%$ \\
Accuracy & $85.3 \%$ & $96.6 \%$ & $81 \%$ & $97 \%$ & $81 \%$ & $96 \%$ \\
PPV & $100 \%$ & & & & & $100 \%$ \\
NPV & $75 \%$ & & & & & $89.74 \%$ \\
\hline
\end{tabular}




\section{Discussion:}

CT guided transthoracic FNAC is a safe and accurate means of diagnosing benign and malignant intrathoracic lesions. In this study, the sensitivity, specificity, accuracy, positive predictive value and negative predictive value of CT guided transthoracic FNAC were $93.85 \%$, $100 \%, 96 \%, 100 \% \& 89.74 \%$ respectively for malignant intrathoracic masses and $94.29 \%$, 98.46\%, 97\%\%, 97.06\% \& 96.97\% respectively for benign masses. These findings are comparable to that of the past studies (Singh et al ${ }^{12}$, Stanely et al ${ }^{14}$, Haramati et al ${ }^{15}$, Mohammad et al ${ }^{16}$, van Sonnenburg et al ${ }^{17}$ ) as shown in table VI.

Out of 100 patients of intra-thoracic mass 36\% were in the age group ranging from 46-55 years and $21 \%$ were in the age group ranging from 56-65 years, these two groups were predominant in terms of age. Out of 100 cases there were 77 men (77\%) and 23 were women (23\%). This correlates with the well-known fact that intrathoracic mass occurs most commonly in older age group and in males than in females. Female cases are less because malignant pulmonary lesions are rare in females in our population. Male: Female ratio was 3.3:1.This is similar with the previous published reports of unguided pulmonary FNAC in Bangladesh.

The locations of the lesions were as follows: pulmonary 67 (67\%), hilar 14(14\%), mediastinal $19(19 \%)$. In the final diagnosis, squamous cell carcinoma was the commonest malignant tumour followed by adenocarcinoma, metastatatic carcinoma and small cell carcinoma. These findings are similar to the findings of the study done by Mostafa ${ }^{18}$ although his study was not guided by CT and the number of cases was less. In some past studies adenocarcinoma was found to be the commonest primary malignant tumour of the lung. They dealt with patients at early stage of their disease but most of the cases in our series were at advanced stage with a huge lesion. In the benign group majority were granulomatous lesions. This finding is similar to Mostafa's study ${ }^{18}$.
All the patients tolerated the procedure well. Complaint of $18(18 \%)$ patients was pain at the puncture site which lasted for few hours (3-6 hours) and subsided without medication. Pneumothorax developed after aspiration in only $13(13 \%)$ patients and single episode of scanty haemoptysis in only $2(2 \%)$ patients. In all 13 cases pneumothorax was noted within 10 minutes of the procedure and it was mild (less than one tenth of chest). None of them required chest tube insertion. The cases of haemoptysis also required no treatment. Our experience is similar to the study of Singh et al 12 where fatal complications like tension pnemothorax, air embolism, endobronchial haemmorhage etc were absent. The complication rate depends on the distance of the lesion from pleura and lesion size. The more the amount of the lung tissue traversed by the needle the more was the complication rate and smaller the lesion the more was the complication rate. In this study fine needle of $23 \mathrm{G}$ was used where the chance of complication seems to be minimum which correlates well with the study of Zaval et al ${ }^{19,20}$.

Thus, though CT guided FNAC underdiagnosed intrathoracic mass in a few cases, it did provide accurate diagnosis in the majority of the cases. Physician's experience of this procedure and location of intrathoracic mass may affect the diagnosis. CT guided FNAC may fail to guarantee a correct diagnosis from small sized lesion( less than $0.5 \mathrm{~cm}$ ), lesion in aortopulmonary window, subcarinal level, under scapula and ribs and if the lesion distance is greater than the needle length . Larger study population can give more precise results regarding diagnostic validity of this method.

\section{Conclusion:}

This study concludes that CT guided transthoracic needle aspiration cytology using 23 gauge spinal needle is a highly sensitive and specific procedure in the diagnosis of thoracic masses that are not approachable by ultrasound. It is a relatively simple procedure with good patient compliance and low morbidity. The use of CT-guided FNAC of intrathoracic lesions reduces the diagnostic interval and 
cost. As the facilities continue to improve, it is likely to have a greater role in the initial evaluation of intrathoracic mass in Bangladesh in the near future.

\section{References:}

1. Singh MM, Gupta RK, Das DK, Pant S. Ultrasonically guided Fine needle aspiration cytology (FNAC) of intrathoracic lesions. Indian $\mathrm{J}$ Chest Dis \& All Sci 1987; 29: 81-9.

2. Kaur S, Kumar B, Gupta SK. Fine needle aspiration of lymph nodes in leprosy- A study of bactariologycal and morphological indices. Int $\mathrm{J}$ Lepr 1997; 45: 369-72.

3. Gupta SK, Kumar B, Kaur S. Aspiration cytology of lymph nodes in leprosy. Int J Lepr 1981; 49: 9-15.

4. Suen KC. Atlas and textbook of aspiration biopsy cytology. Baltimore: Williams \& Wilkins; 1990. p.1-15.

5. Orell SR, Sterrett GF, Walters MN, Whitaker D. Manual and atlas of fine needle aspiration cytology. $2^{\text {nd }}$ ed. Edinburgh: Churchill Livingston; 1992. p. 172-216.

6. Zornoza J, Wallace S, Ordonez N, Lukeman J. Fine needle aspiration cytology of the liver. AJR 1980; 134: 331-4.

7. Rasmussen, Holm HH, Kristensen JK, Barlebo H. Ulrasonically guided liver biopsy. BMJ 1972; 2: 500 .

8. Hancke S, Holm HH, Koch F. Ultrasound guided transthoracic fine needle aspiration biopsy of pancreas. Surg Gynecol Obstet 1975; 140: 361.

9. Kristensen JK, Holm HH, Rasmussen Sw, Barlebo H. Ultrasound guided transthoracicpuncture of renal masses. Scand J Urol Nephron 1972; 15(suppl): 47.

10. Hagga JR. ed. Image-guided microprocedures: CT and MRI interventional procedure. In: CT and MRI
Imaging of the whole body. $4^{\text {th }}$ ed. St.Louis: Mosby; 2003. p. 2123-83.

11. Gupta S, Wallace MJ, Morello AF, Ahar K, Hicks ME. CT-guided transthoracic needle biopsy of intrathoracic masses by using the transsternal approach: experience in 37 patients. Singapore Med J 2002; 43(11): 573-5.

12. Singh JP, Garg L, Setia V. Computed Tomograhy (CT) guided transthoracic needle aspiration cytology in Thoracic mass lesions - not approachable by USG. Ind J Radiol Imag 2004; 14(4): 395-400.

13. Gobien RP, Stanley JH, Vujiic I, Gobien BS. Thoracic biopsy: CT guidance of thin-needle aspiration. Proceedings of the 6th congress of the European society of Cardiovascular and Interventional Radiology and the European College of Angiography. August 30th - September 3rd; 1992. Barcelona, Spain.

14. Stanely JH, Fish GD, Andriole JG. Lung lesions: cytological diagnosis by fine needle biopsy. Radiology 1987; 162: 389-91.

15. Haramati LB. CT-guided automated needle biopsy of the chest. AJR 1995; 165: 53-5.

16. Mohammad GM. CT guided fine needle aspiration cytology in the diagnosis of thoracic lesions. JIMA 2001; 99(10): 1-5.

17. van Sonnenberg E, Casola G, Ho M, et al. Difficult Thoracic Lesions: CT-guided biopsy Experience in 150 cases. Radiology 1988; 167: 457-61.

18. Mostafa MG. Computed tomographic guided fine needle aspiration cytology in the diagnosis of thoracic lesions. J Indian Med Assoc 2001; 99(10): 550-3.

19. Zavala DC, Bedell GN. Transthoraciclung biopsy with a cutting needle. Am Rev Respir Dis 1972; 106: 186-93.

20. Zavala DC, Schoell JE. Ultrathin needle aspiration of lung in infectious and malignant disease. Am Rev Respir Dis 1981; 123: 125-31. 